\title{
VORONOI DIAGRAM BASED SIMULATION AND EXPERIMENTAL VALIDATION OF AUSTENITE IN C22 AND C35 STEELS
}

\author{
S. Sanchu*, N. Biju, V.N.N. Namboothiri \\ Division of Mechanical engineering, SOE, Cochin University of science and technology, \\ Kochi India
}

Received 30.03.2020

Accepted 05.04.2020

\begin{abstract}
This paper examines the ability of power Voronoi diagram assisted simulation in microstructure modeling during heat treatment. A model is developed for predicting fraction of austenite evolved during continuous heating of steel to austenite range, by integrating geometrical features of power Voronoi diagram and classical nucleation theory. From the simulation results, it is possible to predict the transformed fraction. The simulation results are validated using experiments conducted on two varieties of steels. The maximum error obtained is $2.08 \%$. Thus, power Voronoi assisted simulation can be considered as an effective tool in modeling microstructure evolution during austenitization.
\end{abstract}

Keywords: simulation; austenitization; power Voronoi diagram.

\section{Introduction}

Knowledge about evolved microstructure during heat treatment is essential for the cost-effective development of materials with desired properties. The crystalline aggregates of different phases constitute the microstructure of the steel. The amount of phases present in the final structure determines the mechanical properties. Hence, it is crucial to determine the fraction of the evolved phase during heat treatment. In the classical approach, the expression for the transformed fraction is calculated assuming equal probability for nucleation of the product phase in the structure [1-6]. In actual practice, the probability of nucleation, nucleation rate, and growth rate will depend on the structure of the material used. A modular approach transformation kinetics is also available, which considers separate models for nucleation, growth and impingement of new phases both in isothermal and an-isothermal cases [7-9]. Caballero et al. [10] proposed a model of ferrite-austenite phase transformation from various initial microstructure.

*Corresponding author: Sanchu S, sanchusukumaran@gmail.com 
Apart from phase fraction, mesoscale detailed microstructure characters like grain size, grain distribution, and grain shape have an influence on materials properties [11]. The complex spatial and temporal microstructure topology evolving during solidstate phase transformation has been modeled by various techniques, including the Vertex method and Montecarlo model [12-14]. Some other popular methods for microstructure simulation are the phase-field model [15-17] and cellular automata [1820]. The finite element method is another important method widely used to simulate microstructural changes during heat treatment [21]. Software like DEFORM, CODE ASTER, etc. are also available.

The reliability of computer-assisted micro-mechanical analysis depends on accuracy in inputting microstructure properties. Modeling of microstructure from optical micrographs or SEM images is one method. Voronoi diagram is widely used for developing a statistically similar microstructure [23] from SEM or optical microscope images. Many reports are available in the literature, regarding the effectiveness of Voronoi algorithm-based microstructure development [23-27]. Voronoi diagram is a technique for partitioning $n$-dimensional Euclidean space. If a finite number of distinct points is given in a continuous space, each point in space can be associated with any of the given points based on some criteria. If the region is divided in such a way that the distance from the given point to the point under consideration is minimum, the result will be the Voronoi diagram [22].

Mathematical models of heat treatment operations provide an attractive tool for analyzing and optimizing heat treatment procedures [21]. Heat treatment of steel generally consists of heating above the austenitization temperature, holding period, and cooling. Heating steel from normal temperature to austenite region is known as austenitization. Re-crystallization of austenite has great influence on the microstructure of the steel. The formation of austenite follows the general rules of solid-state phase transformation; it is accomplished through nucleation and growth [21]. Publications describing the underlying mechanism of austenite transformations including the kinetics of austenite transformation, transformations from various initial microstructures, stages of nucleation, growth, and velocities of different interfaces, are available in the literature [28-34].

This work is an attempt to simulate microstructure evolution during continuous heating to austenite range, using the power Voronoi diagram. Geometrical properties of power Voronoi diagram is incorporated with classical nucleation theory to simulate evolved microstructure during austenitization and thus to predict the transformation kinetics. The power Voronoi diagram is a special case of weighted Voronoi diagrams. It is generated using additively weighted power distance or simply power distance. It is characterized by the weighted distance given by $d_{a w}\left(P_{i}, P_{j}\right)=\left\|X-X_{i}\right\|^{2}-W_{i}, W_{i}>0$ [22].The simulation was done using MATLAB.From the results, it is possible to calculate the fraction of austenite formed. The simulated microstructure at various temperatures is validated against experimental results.

\section{Materials and methods}

In this work, a model to describe ferrite + pearlite to austenite transformation during continuous heating is formulated using the Power Voronoi diagram. The model validation is done using micrographs obtained at various temperatures. 


\section{Computational model}

The materials used in this work are $\mathrm{C} 35$ and $\mathrm{C} 22$; its composition is given in table 1.

Table 1. Material composition in weight percentage.

\begin{tabular}{lllllllllll}
\hline Material & $\mathrm{C}$ & $\mathrm{Mn}$ & $\mathrm{Si}$ & $\mathrm{Cu}$ & $\mathrm{Cr}$ & $\mathrm{Ni}$ & $\mathrm{Mo}$ & $\mathrm{Sn}$ & $\mathrm{P}$ & $\mathrm{S}$ \\
\hline C35 & 0.364 & 0.656 & 0.305 & 0.226 & 0.177 & 0.092 & 0.016 & 0.017 & 0.014 & 0.021 \\
$\mathrm{C} 22$ & 0.214 & 0.513 & 0.200 & 0.086 & 0.021 & 0.049 & 0.003 & 0.003 & 0.019 & 0.031 \\
\hline
\end{tabular}

Austenitisation progresses in two simultaneous processes- nucleation and growth [21]

\section{Nucleation}

The difference in Gibb's free energy between the parent phase and the final phase is the driving force for phase transformation. When the difference in free energy is subsequently high, a small volume of product phase called nuclei will form, and later it will grow. According to classical nucleation theory (CNT), driving pressure for nucleation is the decrease in Gibb's free energy per unit volume. The difference in Gibb's free energy depends on chemical composition, temperature, and many other factors. Under conditions of homogeneous nucleation, austenite grain nucleation intensity (I) can be defined as a function of temperature [21] as

$$
I=C \exp \left(-\frac{\left(Q_{D}+W\right)}{k T}\right)
$$

where

$\mathrm{C}$ is a constant

W - Critical nucleation work, $\mathrm{J}$

$\mathrm{T}$-Temperature, $\mathrm{K}$

$\mathrm{Q}_{\mathrm{D}}$ - Activation energy of diffusion, $\mathrm{J}$

$\mathrm{k}$-Boltzmann constant $\left(1.38 \times 10^{-23} \mathrm{~J} / \mathrm{K}\right)$

Critical nucleation work can be represented by [33]

$$
W=\frac{A \sigma^{3}}{\Delta g_{v}^{2}}
$$

Where

A is a constant

$\sigma$ is the energy of austenite ferrite interface per unit area

$\Delta \mathrm{g}_{\mathrm{v}}$ is the difference in Gibb's free energy between ferrite and austenite (J)

The nucleus volume can be given as $Z_{v} R^{3}$ where $Z_{v}$ is a geometrical parameter depends on shape of nucleus and $\mathrm{R}$ is the nucleus dimension. The interface area is given by $\mathrm{z}_{\mathrm{A}} \mathrm{R}^{2}$. The critical radius $\mathrm{R}^{*}$ is defined by value of $\mathrm{R}$ when $\mathrm{W}$ is maximum and is given by [34] 


$$
R^{*}=\frac{2 \sum_{i} Z_{A} \sigma_{i}}{3 Z_{v} \Delta g_{v}}
$$

The corresponding activation energy for nucleation

$$
W=\frac{4}{27} \frac{\left(\sum_{i} Z_{v}^{i} \sigma_{i}\right)^{3}}{Z_{v}^{2} \Delta g_{v}^{2}}=\frac{\psi}{\Delta g_{v}^{2}}
$$

With

$$
\psi=\frac{4}{27 Z_{v}^{2}}\left(\sum_{i} Z_{v}^{i} \sigma_{i}\right)^{3}
$$

Nucleation intensity in $\mathrm{m}^{-3} \mathrm{~s}^{-1}(\mathrm{I})$ can be calculated using the following equation [35]

$$
N \alpha\left(1-f^{\alpha}\right) \frac{k T}{h} \exp \left[-\frac{\frac{\psi}{\Delta g_{v}{ }^{2}}+Q_{d}}{k T}\right]
$$

where

$\mathrm{N}$ is the nucleation rate

$\mathrm{f}^{\alpha}$ - already transformed fraction

$\mathrm{k}$ - Boltzman constant $1.38 \times 10^{-23} \mathrm{~J} / \mathrm{K}$

h - Planks constant $6.626 \times 10^{-34} \mathrm{~J} / \mathrm{s}$

$\mathrm{T}$-the temperature in $\mathrm{K}$

$\mathrm{Q}_{\mathrm{d}^{-}}$activation energy of diffusion in $\mathrm{J}$

$\psi$ factor represents the energy balance between the energy required for the formation of new interface and energy released due to the removal of the old interface.

$\Delta \mathrm{g}_{\mathrm{v}}$ is the difference in Gibb's free energy between the parent phase and product phase

The values of $\psi$ and $\mathrm{Q}_{\mathrm{d}}$ were taken as $5 \times 10^{-8} \mathrm{~J}^{3} / \mathrm{m}^{6}$ and $4.72 \times 10^{-19} \mathrm{~J}$ as reported by Offerman et al. [35]. $\Delta \mathrm{g}_{\mathrm{v}}$ at different temperatures were calculated using the following equations [34]

$$
G=(1-y) G_{F e}^{0}+y G_{F e c / a}^{0}+y(1-y) \frac{c}{a} L_{c, v}+R T \frac{c}{a}\{y \ln y+(1-y) \ln (1-y)\}
$$


where

(for ferrite)

$$
\begin{aligned}
G_{F e}{ }^{0}=1224.83+ & 124.134 T-23.5143 T \ln (T)-0.00439752 T^{2} \\
& -5.89269 \times 10^{-8} T^{3}+77358.5 T^{-1}+\frac{1}{1-y} G_{m a g}+H_{F e}^{r e f} \mathrm{~J} / \mathrm{mole}
\end{aligned}
$$

$G_{F e c / a}^{0}=322050+75.667 T+G_{F e}^{0}+\frac{c}{a} G_{\text {graphite }}^{0} J /$ mole

$\mathrm{G}_{\text {mag }}=-9180.5+9.723 T-9309.8\left(\frac{\tau^{4}}{6}+\frac{\tau^{10}}{135}+\frac{\tau^{16}}{600}\right) J /$ mole $\quad(\tau<1)$

$\mathrm{G}_{m a g}=-6507.7\left(\frac{\tau^{-4}}{10}+\frac{\tau^{-14}}{315}+\frac{\tau^{-24}}{1500}\right) J /$ mole $\quad(\tau>1)$

$\tau=\frac{T}{T_{c}}$

$\frac{c}{a} L_{c, v}=-190 T J /$ mole

$\frac{c}{a}=3$

for Austenite

$G_{F e}{ }^{0}=-237.57+132.416 T-24.6643 T \ln (T)-0.00375752 T^{2}-5.89269 \times 10^{-8} T^{3}$

$$
+77358.5 T^{-1}+H_{F e}^{r e f} \mathrm{~J} / \text { mole }
$$

$G_{F e c / a}^{0}=77207-15.877 T+G_{F e}^{0}+\frac{c}{a} G_{\text {graphite }}^{0} J /$ mole

$\frac{c}{a} L_{c, v}=-34671 /$ mole 
$\frac{c}{a}=1$

Where $T_{c}$ is the curie temperature of ferrite $1043 \mathrm{~K}$ and

$$
\begin{gathered}
G_{\text {graphite }}^{0}=-17369+170.73 T-24.3 T \ln (T)-4.723 \times 10^{-4} T^{2}+2562600 T^{-1} \\
-2.643 \times 10^{-8} T^{-2}+1.2 \times 10^{10} T^{3}+H_{c}^{\text {ref }} \mathrm{J} / \mathrm{mole}
\end{gathered}
$$

and

$H_{F e}^{r e f}$ is $4489 \mathrm{~J} / \mathrm{mole}$ and $H_{c}^{\text {ref }}$ is $1054 \mathrm{~J} / \mathrm{mole}$

$$
y=\frac{a}{c}\left(\frac{x}{1-x}\right)
$$

$\mathrm{x}$ is the atom fraction of $\mathrm{C}$ in $\mathrm{Fe}-\mathrm{C}$ alloy

\section{Growth}

The velocity of the austenite interface in the pearlite region and ferrite region needed to be determined to incorporate growth kinetics in the model. The average velocity of austenite interface in the perlite colony was calculated by considering diffusion kinetics of carbon in austenite. For the typical value of lamellar spacing $\mathrm{L}=0.5$ $\mu \mathrm{m}$ in pearlite, the growth rate was estimated as $1.4 \mu \mathrm{m} / \mathrm{s}[37,38]$. The interface velocity in the ferrite region can be calculated as $[37,38]$

$$
\frac{d z_{\gamma \alpha}}{d t}=\frac{J^{\alpha}}{x_{\gamma \alpha}^{C_{e q}}-x_{\alpha \gamma}^{C_{e q}}}
$$

where

$\mathrm{Z}_{\gamma \alpha}$ is the carbon diffusion distance from the source of carbon to the austenite nucleus. $\mathbf{J}^{\alpha}$ flux of carbon atoms $x_{\gamma \alpha}^{C_{e q}}$ and $x_{\alpha \gamma}^{C_{e q}}$ are the para-equilibrium carbon concentrations.

Taking average distance equal to $30 \mu \mathrm{m}$ the austenite-ferrite interface velocity can be calculated as $0.03 \mu \mathrm{m} / \mathrm{s}[37,38]$.

\section{Formulation of austenite formation}

Austenitisation is happening in two stages, nucleation and growth. By identifying the number of nuclei formed at different temperatures and growth rates, it is possible to simulate microstructure using the power Voronoi diagram. In this work, the simulation was done on a $200 \times 200 \mu \mathrm{m}^{2}$ space. Classical nucleation theory was used to determine the number of nuclei formed at each temperature. The probability of nucleation in pearlite and ferrite interface is taken as seven times greater than in the internal perlite 
region based on the activation energy [19]. From equation (6) the nucleation rate in $\mu \mathrm{m}^{2} \mathrm{~s}^{-1}$ (I) at various temperatures was calculated. The activation energy ( $\mathrm{Q}_{\mathrm{D}}$ ) for diffusion in $\mathrm{C} 35$ steel is calculated as $4.72 \times 10^{-19} \mathrm{~J}$ [35]. Offerman et al. experimentally determined $\psi[35]$ as $5 \times 10^{-8} \mathrm{~J}^{3} / \mathrm{m}^{6}$. The difference in Gibb's free energy $\left(\Delta \mathrm{g}_{\mathrm{v}}\right)$, at various temperatures, was calculated using equations 7 and 8 described in the previous section. In equation (8) $\mathrm{c} /$ value was taken as 3 [35] and atom fraction of $\mathrm{C}$ in $\mathrm{Fe}-\mathrm{C}$ was calculated as 0.214 . The growth rate for austenite in the pearlite region and ferrite region was taken as described in section 2.3.

During heating, nuclei of austenite were formed in the parent structure and they started growing. The microstructure after heating depends on the position and time of the birth of product nuclei. With the increase in time available for growth, the grain size increases. These aspects incorporated in power Voronoi diagram construction. Power Voronoi diagram was used to predict the microstructure during heating to austenite range. The input requirements of the power Voronoi diagram are the position of each point (nucleus) and weight. In each time step, depending upon the temperature, numbers of nuclei were formed. The position of each nucleus determined randomly. Constraints are applied to limit the number of nuclei in each region based on probability. The weight of each nucleus was taken as the time available for the growth. Using this position and weight, power Voronoi diagram was constructed. The simulation was done using MATLAB. Already available MALAB codes were used for the construction of the power Voronoi diagram.

\section{Algorithm}

At time zero, generate $n$ initial points. $n$ is the total number of grains in the initial microstructure. Save the coordinates of points in an array and assume its weight as zero. Input heating rate, heating duration, maximum temperature, and growth rates of product phases.

Step1: Increase time by one-step; update temperature based on the heating rate. Check whether the temperature reached the maximum; if yes, go to step5. Check whether the temperature falls in the austenite formation region. If yes, generate $m$ number of product nuclei. Otherwise, go to step 4.

Step2: Check the position of each nucleus. Based on the initial microstructure, determine the region in which each nucleus falls. Check (a) any product nuclei coincide with parent nuclei; if yes, delete parent nuclei (b) any product nuclei coincide with product nuclei, delete newly generated product nuclei. (c) Check any newly generated product nuclei falls in the influence region of old product nuclei if so, delete newly generated product nuclei.

Step3: Update the matrix by eliminating the deleted nuclei and adding the product nuclei. Assign weight corresponding to the birth time and velocity to each product nuclei.

Step4: Check whether time reaches heating duration; if no, go to step 1.; if yes, go to step 6.

Step5: Check any parent nucleus was in the influence region of product nuclei. If yes, delete parent nuclei. Update matrix. Check whether time reaches heating duration. If no, go to step 1. If yes, go to step6.

Step6: Draw power Voronoi diagram using the nuclei as generated points and corresponding weights. 

weights.

Step7: Calculate the area of Voronoi polygon for generator points with non-zero formed.

Step8: Divide this value with the total area. Gives the fraction of austenite

\section{Simulation results}

Micrographs of C35 and C22 steel at room temperature were read to MATLAB in order to determine the ferrite and pearlite regions in the initial microstructure. Figure 1(a) represents the microstructure of $\mathrm{C} 22$ and 1(b) represents the microstructure of $\mathrm{C} 35$ steels with 50x magnification at room temperature. Based on the pixel, pearlite and ferrite regions were identified. Simulations were run for temperatures 760 and $775{ }^{\circ} \mathrm{C}$ for two different heating rates $3{ }^{\circ} \mathrm{C} / \mathrm{min}$ and $5{ }^{\circ} \mathrm{C} / \mathrm{min}$. The resultant microstructure is shown in figure 2. In order to minimize error, the transformed fraction was taken as the average result obtained from fifty simulation runs in each case. The simulation results were shown in figure 2 and the calculated fraction is tabulated in Table 2.

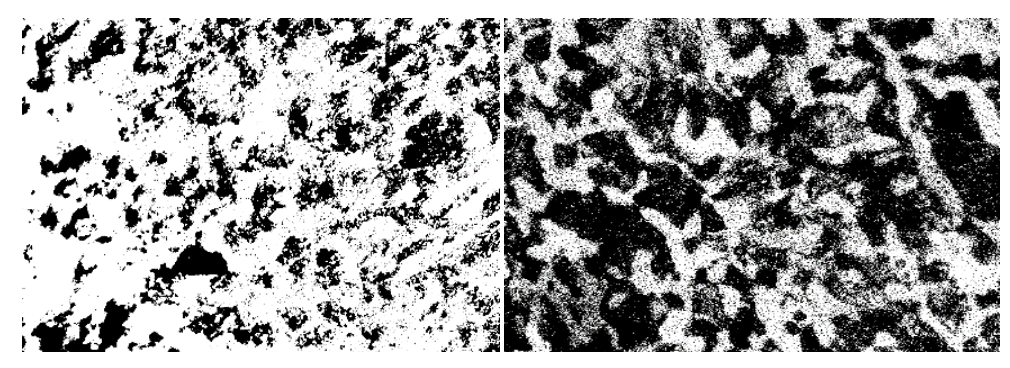

$$
\begin{array}{ll}
C 22 & \text { (b) } C 35
\end{array}
$$

Fig.1. Initial microstructure of $C 22$ and C35, 50x magnification.

Table 2. Austenite fraction at various temperatures - simulation results.

\begin{tabular}{llll}
\hline Heating rate & Temperature & $\begin{array}{l}\text { Material } \\
\mathrm{C} 22\end{array}$ & $\mathrm{C} 35$ \\
\hline $3{ }^{\circ} \mathrm{C} / \mathrm{min}$ & 760 & 0.59 & 0.6 \\
& 775 & 0.75 & 0.76 \\
$5{ }^{\circ} \mathrm{C} / \mathrm{min}$ & 760 & 0.48 & 0.49 \\
& 775 & 0.658 & 0.71 \\
\hline
\end{tabular}




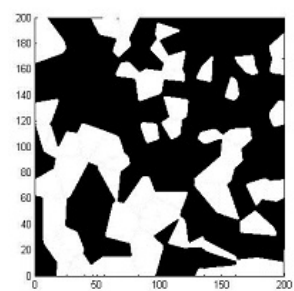

(2) $760^{\circ} \mathrm{C} @ 3^{\circ} \mathrm{C} / \mathrm{min}$

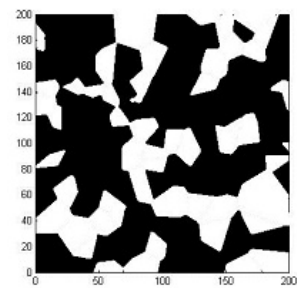

(e) $760^{\circ} \mathrm{C} @ 3^{\circ} \mathrm{C} / \mathrm{min}$

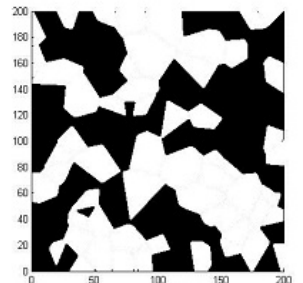

(b) $760^{\circ} \mathrm{C} @ 5^{\circ} \mathrm{C} / \min$

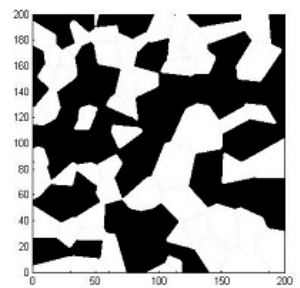

(f) $760^{\circ} \mathrm{C} @ 5^{\circ} \mathrm{C} / \min$

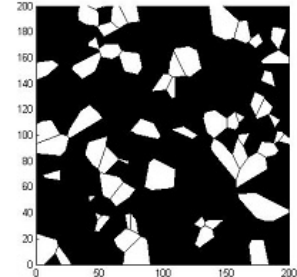

(c) $775^{\circ} \mathrm{C} @ 3^{\circ} \mathrm{C}$ min

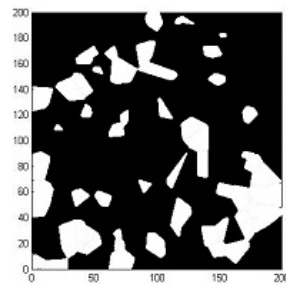

(g) $775^{\circ} \mathrm{C} @ 3^{\circ} \mathrm{C} / \min$

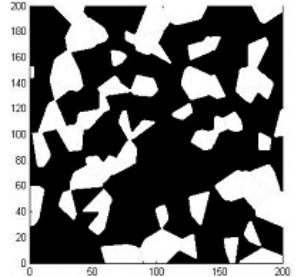

(d) $775^{\circ} \mathrm{C} @ 5^{\circ} \mathrm{C} / \min$

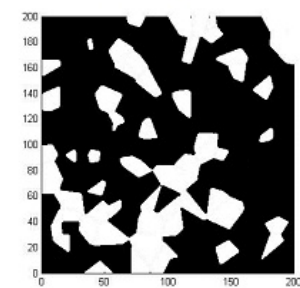

(h) $775^{\circ} \mathrm{C} @ 5^{\circ} \mathrm{C} / \mathrm{min}$

Fig. 2. Simulated microstructure of C22 and C35 at different temperatures (a) -(d) C22 and (e)-(h) C35.

\section{Experimental results and Validation}

In order to validate the model, the following experimental procedure was used. Two varieties of steels were heated to two different temperatures, using two different heating rates. Specimens were water quenched, and a fraction of phases present in it was calculated analyzing optical microscope images. Obtained phase fractions were compared with the phase fraction calculated from the simulated results. The alloys used in the experiment are C35 and C22. Details of composition are shown in table 1. The ferrite and pearlite in the initial microstructure of $\mathrm{C} 35$ and $\mathrm{C} 22$ steels consist of 58\% and $42 \%$, and $73 \%$ and $27 \%$ respectively. The samples were heated to $760{ }^{\circ} \mathrm{C}$ and 775 ${ }^{\circ} \mathrm{C}$ with a heating rate of $3{ }^{\circ} \mathrm{C} / \mathrm{min}$ and $5{ }^{\circ} \mathrm{C} / \mathrm{min}$. They were taken out and water quenched. Each specimen was ground, polished using a diamond paste, and then etched with a $4 \%$ Nital solution. Micrographs of specimens, heat-treated and at room temperature were taken. The micrographs at each temperature are presented in figure 2. The transformed fraction at each temperature was evaluated from the micrographs. The micrographs at each temperature were processed using an open-source software ImageJ (39). Image segmentation was done to evaluate the fraction of phases present in the specimens. The process followed the procedure published by Gupta et al. [40] which includes histogram equalization, Otsu thresholding, dilation, SLIC segmentation, SLIC thresholding, phase masking, SLIC closing morphology and phase segmentation. Phase fraction obtained is represented in table 3 . 
Table 3. Austenite fraction at various temperatures.

\begin{tabular}{llll}
\hline Heating rate & Temperature & $\begin{array}{l}\text { Material } \\
\mathrm{C} 22\end{array}$ & $\mathrm{C} 35$ \\
\hline $3{ }^{\circ} \mathrm{C} / \mathrm{min}$ & 760 & 0.6 & 0.61 \\
& 775 & 0.75 & 0.75 \\
$5^{\circ} \mathrm{C} / \mathrm{min}$ & 760 & 0.49 & 0.48 \\
& 775 & 0.65 & 0.70 \\
\hline
\end{tabular}

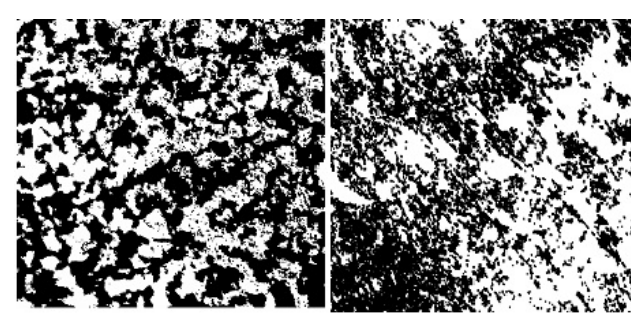

(a) $760^{\circ} \mathrm{C} @ 3^{\circ} \mathrm{C} / \mathrm{min}$

(a) $760^{\circ} \mathrm{C} @ 5^{\circ} \mathrm{C} / \mathrm{min}$

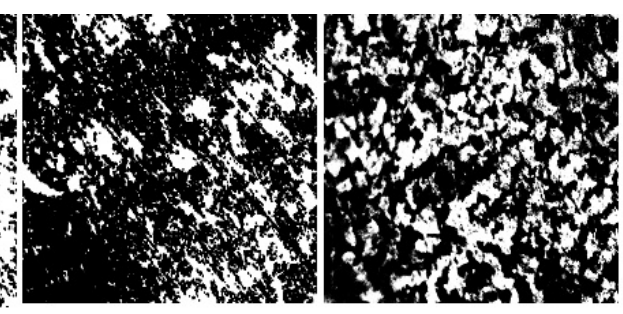

(c) $775^{\circ} \mathrm{C} @ 3^{\circ} \mathrm{C} / \mathrm{min}$ (d) $775^{\circ} \mathrm{C} @ 5^{\circ} \mathrm{C} / \mathrm{min}$

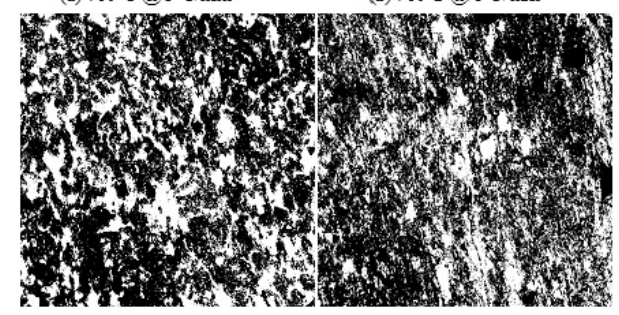

(e) $760^{\circ} \mathrm{C} @ 3^{\circ} \mathrm{C} / \min$

(f) $760^{\circ} \mathrm{C} @ 5^{\circ} \mathrm{C} / \mathrm{min}$

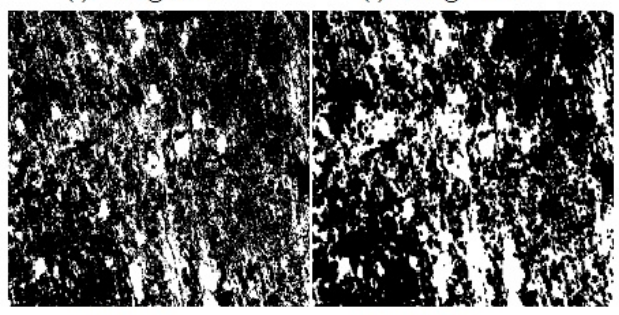

(g) $775^{\circ} \mathrm{C} @ 3^{\circ} \mathrm{C} / \mathrm{min}$

(h) $775^{\circ} \mathrm{C} @ 5^{\circ} \mathrm{C} / \min$

Fig. 3. Micrographs of C22 and C35 at different temperatures after processing (a) -(d) C22 and (e)-(h) C35, 50x magnification.

The fraction of austenite at each temperature, obtained from the experimental results, was compared with phase fraction calculated from simulation results. Percentage error between the austenite fraction calculated from simulation and obtained from the experiment, corresponding to each temperature, each material and for each heating rate is shown in table 4.

Table 4. Percentage error between simulated and experimentally calculated austenite fraction.

\begin{tabular}{llll}
\hline $\begin{array}{l}\text { Heating } \\
\text { rate }\end{array}$ & Temperature & $\begin{array}{l}\text { \% Error between simulated and experimental results } \\
\text { Material } \\
\mathrm{C} 22\end{array}$ \\
\hline $3^{\circ} \mathrm{C} / \mathrm{min}$ & 760 & 1.67 & $\mathrm{C} 35$ \\
& 775 & 0 & 1.64 \\
$5^{\circ} \mathrm{C} / \mathrm{min}$ & 760 & 2.04 & -1.33 \\
& 775 & -1.23 & -2.08 \\
\hline
\end{tabular}


In the case of $\mathrm{C} 22$ steel, the simulated results have good agreement with experimental results. For $3{ }^{\circ} \mathrm{C} / \mathrm{min}$ and $5{ }^{\circ} \mathrm{C} / \mathrm{min}$ heating rates, error values are $1.67 \%$, $0,2.04 \%$ and $-1.23 \%$. The maximum deviation is $2.04 \%$. In the case of C35 steel, also the maximum error is $-2.08 \%$. From the results, it is obvious that a power Voronoi diagram is an efficient tool for predicting transformation kinetics during austenitization. Other parameters like grain size, grain distribution and grain shape etc. need to be analyzed further to explore the capabilities of power Voronoi modeling in the field of prediction of microstructure evolution during heat treatment.

\section{Conclusion}

Simulation of microstructure evolution during continuous heating to austenite range was done with the help of the power Voronoi diagram. Classical nucleation theory was used to calculate the rate of nucleation at different temperatures. From the results, it was possible to predict the fraction of austenite in the structure at each temperature. The simulation results were validated against experimental results. For that, two varieties of steels were heated to the austenite region at different heating rates, followed by quenching. Optical micrographs thus obtained were analyzed to identify the austenite fraction before quenching. Obtained results were compared with the simulation results. It is clear that transformed fraction can be predicted with greater than $97 \%$ accuracy in all cases. Thus, power Voronoi Simulation can be considered as an efficient tool for predicting the evolution of microstructure during austenitization.

\section{Acknowledgment}

The authors are grateful to Prof.M R RPanicker for helpful discussions and for sharing experimental facilities. The authors would like to thank Prof.Jayesh for the supports given during experimental work.

\section{References}

[1] Totten, George E. Steel heat treatment metallurgy and technologies, second edition, CRC press, 2004.

[2] William A Johnson, Robert F Mehl: Trans AIME, 135 (1939) 416-458.

[3] Melvin Avrami: J Chem Phys, 7 (1939) 1103-1112.

[4] Melvin Avrami: J Chem Phys, 8 (1940) 212-224.

[5] Melvin Avrami: J Chem Phys, 9 (1941) 177-184.

[6] Kolmogorov, A N: Izv. Akad. Nauk. Ser. Mat., 3(1937) 355-360.

[7] F. Liu, F. Sommer, C. Bos, E. J. Mittemeijer: Int Mater Rev, 52 (2007) 193-212.

[8] A.T.W. Kempen, F. Sommer, E.J. Mittemeijer: J Mater Sci, 37 (2002) 13211322.

[9] F. Liu, F. Somer, E.J. Mittemeijer: J Mater Sci, 39 (2004) 1621-1634.

[10] F G Caballero, C. Capdevila, Garcia De Andres: ISIJ Int, 41(2001) 1093-1102.

[11] Jiansheng Pen CemilHakan Gur: Thermal process modeling of steel, First edition, CRC Press, 2009, 313-337.

[12] 12.M. Miulitzer: ISIJ Int, 47 (2007), 1-15.

[13] D. Weaire, J. A. Glazier: Mater Sci Forum, 27 (1992) 94-96.

[14] D. Rabbe: Annu Rev Mater Res, 32 (2002) 53-76.

[15] Zhao hong-zhuang, LIU Xing-hua, Wang Guo-dong: J Iron Steel Res Int, 13 (2006) 68-73. 
[16] Qin R S: Mater Manuf Processes: 26 (2011) 132-136.

[17] Oleg Shchyglo, Guanxing Du, Jenni K Engels, Ingo Steinbach: Acta Mater, 175 (2019) 415-425.

[18] S. Raghavan, S.S. Sahay: Mater SCiEng A, 445-446 (2007) 203-209.

[19] B.J. Yang, A. Hittiangadi, W.Z. Li, G.F. Zhou, T.E. McGreevy: Mater Sci Eng, A 527 (2010) 2978-2984.

[20] B.J. Yang, L. Chuzhoy, M.L. Johnson: Comput Mater Sci, 41 (2007) 186-194.

[21] Jiansheng Pen CemilHakan Gur: Thermal process modeling of steel, First edition, CRC Press, 2009, 90-112.

[22] A. Okabe, B. Boots, K. Sugihara, S. Nok Chiu: Spatial tessellations, second edition, JohnWiley and sons Ltd, 2000.

[23] S. Kanthi, S. Ziaei-Rad, N. Nouri, N. Saeidi, J. Kadkhodapour, N. Torabian, S. Schmauder: MetallogrMicrostruct Anal, 2 (2013) 156-169.

[24] M. Nygards, P. Gudmundson: Mater Sci Eng A, 325 (2002) 435-443.

[25] M. Nygards, P. Gudmundson: Comput Mater Sci, 24 (2002) 513-519.

[26] N. Ishikawa, D.M. Parks, S. Socrate, M. Kurihara: ISIJ Int, 40 (2000) 11701179.

[27] H. Koushyar, B. Tavakol, V. Madhvan: Proceedings of fourth annual GRASP symposium, Wichita State university, 2008, 45-46.

[28] F.G. Caballero, C. Capdevila, C. Garcia: Mater Sci Technol, 17 (2001) 11141118.

[29] G.R Speich, V.A. Demarest, R.L. Miller: Metall Trans A, 12 (1981) 1419-1428.

[30] G.R. Speich and A. Szirmae: Trans TMS-AIME, 1969, vol. 245, p. 1063.

[31] D.P. Gokhale, A.M. Datta: Metall Trans A, 12 (1981) 443-450.

[32] R.C. Knorovsky, C.V. Dykhuizen, G.A. Robino: Metall Mater Trans B, 30 (1999) 107-117.

[33] E. Schmidt, Y. Wang, S. Sridhar: Metall Mat Trans A, 37 (2006) 1799-1810.

[34] V.I. Savran, S.E. Offerman, J. Sietsma: Metall Mat Trans A, 41 (2010) 583-591.

[35] G.P. Krielaart, M. Onink, K.M. Brakman, F.D. Tichelaar, E.J. Mittemejer, S. van der Zwaag: ZeitschriftfuerMetallkunde, 11 (1994) 756-765.

[36] S.E. Offerman, N.H. Ven Dijk, E.M. Lauridseno: NuclInstrum Methods Phys, 246 (2006) 194-200.

[37] D. Gaude-Fugarolas, H.K.D.H. Bhadeshia: J Mater Sci, 38(2003) 1195-1201.

[38] V.I. Savran: Austenite formation in C-Mn steel, $\mathrm{PhD}$ Thesis, https://repository.tudelft.nl/islandora/object/uuid:dc98061c-304f4b06b23ee620c51cc190/datastream/OBJ/download

[39] J. Schindelin, I. Arganda-Carreras et al.: Nat Methods, 9 (2012) 676-682.

[40] S. Gupta, J. Sarkar, A. Banerjee, N.R. Bandyopadhyaya, S. Ganguly: Inst Eng India Ser D, 100 (2019) 203-210.

[41] J.W. Christian: The theory of transformations in metals and alloys, third edition, 2002, 797-813.

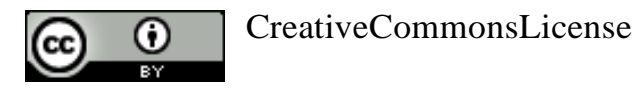

This work is licensed under a Creative Commons Attribution 4.0 International License. 